\title{
Influence Research for Softening and Swelling of Weakly Cemented Soft Rock on the Stability of Surrounding Rock in Roadway
}

\author{
Yan Li $\mathbb{D}^{\text {, }}$, Chao Ma $(\mathbb{D}$, Lianying Zhang $\mathbb{D}$, and Bing Li $\mathbb{D}$ \\ Xuzhou University of Technology, Xuzhou 221000, China \\ Correspondence should be addressed to Chao Ma; mbqq2008@126.com
}

Received 1 December 2021; Revised 11 January 2022; Accepted 17 January 2022; Published 21 February 2022

Academic Editor: Tianran Ma

Copyright ( 2022 Yan Li et al. This is an open access article distributed under the Creative Commons Attribution License, which permits unrestricted use, distribution, and reproduction in any medium, provided the original work is properly cited.

\begin{abstract}
In order to study the influence of the softening and swelling of weakly cemented soft rock on the stability of roadway surrounding rock, based on the background of the general return airway in the south wing of Yuwu coal mine, 4 different schemes are designed according to whether the softening or swelling effect of weak cemented soft rock is considered. Based on the numerical simulation program, FLAC ${ }^{3 \mathrm{D}}$ was used to analyze the distribution characteristics of the shear stress, displacement, and plastic zone of the surrounding rock of the roadway under these 4 designs. On this basis, in view of the geological conditions of the roadway, a new type of "grouting + anchor cable mesh + bottom arch" combined support plan is proposed. The research results show that, under the conventional anchor-net-cable-spraying support scheme, the surrounding rock of the roadway can remain stable without considering the softening and expansion of the weakly cemented soft rock in contact with water and its maximum displacement and plastic zone depth are only $66.9 \mathrm{~mm}$ and $2.8 \mathrm{~m}$. When considering the softening and swelling of weakly cemented soft rock roadways, due to the synergistic effect of the two, the maximum displacement of the surrounding rock of the roadway and the depth of the plastic zone will reach $517.4 \mathrm{~mm}$ and $6.7 \mathrm{~m}$, respectively, which will continue to increase with excavating along the roadway and lead to ultimately destabilization and destruction. After adopting the combined support of "grouting + anchor cable mesh + bottom arch," the maximum displacement of the surrounding rock of the roadway and the depth of the plastic zone will be reduced by $77.1 \% \sim 92.0 \%$ and $18.7 \% \sim 72.4 \%$, respectively, and they will basically remain stable after excavation of 5 days.
\end{abstract}

\section{Introduction}

Weakly cemented soft rock, such as carbonaceous mudstone, mudstone, and silty mudstone, is distributed widely in the top and floor of coal seams in central and western China under the influence of geological tectonics [1-4]. Because the low strength, loose cementation, and poor performance of this rock, especially water, will result in softening and expansion, it is always sustainable growth and serious deformation of surrounding rock when tunneling in weak cemented soft rock roadway, drenched by water, leading to some accidents, including the floor heave, roof caving, and collapse, which seriously restrains efficient coal mine production safety [5-9].

Aiming at the stability control problem of surrounding rock in weakly cemented soft rock roadway under the condition of abundant water, Zhao et al. [10], Li et al. [11], Zhang et al. [12], and Liu et al. [13] carried out some experimental researches on the hydrodynamic characteristics of weakly cemented soft rock and obtained the variation rules of softening, expansion, and deformation parameters of weakly cemented soft rock with its water content or immersion time. Combining numerical simulation and field measurement, Jing and Chen [14], Zhu et al. [15, 16], Hu et al. [17], and $\mathrm{Hu}$ [18] analyzed the deformation and failure characteristics of surrounding rock of water-rich and weakly cemented soft rock roadway. Some supporting schemes, such as "bolt and cable combined support," "two layers of steel mesh sandwiching concrete shotcrete layer + anchor cable grouting," and "steel mesh roof protection + long and short anchor cable + channel steel beam," have been put forward and achieved good application effect. However, the 
above research results rarely show the combination of laboratory test results and practical engineering practice, resulting in the fact that the influence mechanism of water softening and expansion of weakly cemented soft rock on deformation and failure of roadway surrounding rock is not very clear. Therefore, in this paper, based on the background of the general return airway in the south wing of Yuwu coal mine, a trilinear strain-softening model is introduced to change the strength and volume parameters of weakly cemented soft rock before and after flooding to reflect its water-softening and expansion characteristics. On this basis, numerical software FLAC ${ }^{3 \mathrm{D}}$ is used to analyze the distribution characteristics of the shear stress, displacement, and plastic zone of the surrounding rock of the roadway under four conditions, which are designed according to whether the softening or swelling effect of weak cemented soft rock is considered. In addition, a new type of "grouting + anchor cable mesh+bottom arch" combined support plan is proposed.

\section{Engineering Situation}

Yuwu Coal Industry Co. LTD is located $23 \mathrm{~km}$ southwest of $\mathrm{Lu}$ 'an Mining Group in the north of Houzhuang Village, about $35 \mathrm{~km}$ away from Changzhi City and $11 \mathrm{~km}$ away from Changcun Coal Mine. The general situation of its south wing return airway is shown in Figure 1. The cross section of the total return airway in the south wing of Yuwu Coal Industry Co. LTD is $5.2 \mathrm{~m}$ wide and $4.4 \mathrm{~m}$ high, and the buried depth is $1.55 \mathrm{~m}$. The vertical and horizontal stresses are $12.8 \mathrm{MPa}$ and 19.2 $\mathrm{MPa}$, respectively. According to the surrounding borehole bar chart, the strata on top and bottom mainly consist of coal rock, mudstone, sandy mudstone, and medium and fine sandstone, shown in Figure 2. Among them, mudstone and sandy mudstone are weakly cemented soft rock, which is easy to sliming and expansion in the water, while the fractures of medium and fine sandstones are highly developed and water-rich.

The original support scheme of the roadway is designed as the combined support of bolt mesh cable and shotcrete, shown in Figure 3. The row distance between the left rebar bolts in the roof is $800 \mathrm{~mm} \times 800 \mathrm{~mm}$, with the diameter of $22 \mathrm{~mm}$ and the length of $2500 \mathrm{~mm}$. The roof prestressed steel strand anchor cables are arranged in three-flowers distribution, with row spacing of $2400 \mathrm{~mm} \times 2400 \mathrm{~mm}$, diameter of $17.8 \mathrm{~mm}$, and the length of $6300 \mathrm{~mm}$. The roof and two sides of the roadway are supported by metal mesh shotcrete with $100 \mathrm{~mm}$ thick, while C25 plain concrete with $200 \mathrm{~mm}$ thick is used to support to bottom of the roadway. However, it is found that a large number of fracture channels in roof and floor of roadway after excavation for a period of time, due to excavation damage in weakly cemented soft rock, result in adjacent fracture water in fine sand strata flowing into it, which causing liming and expansion. In addition, instability of large deformation occurred, such as roof subsidence, intensive floor heave, anchor bolt fracture, and pallet drops, leading to serious threats to stability control of surrounding rock of roadway.

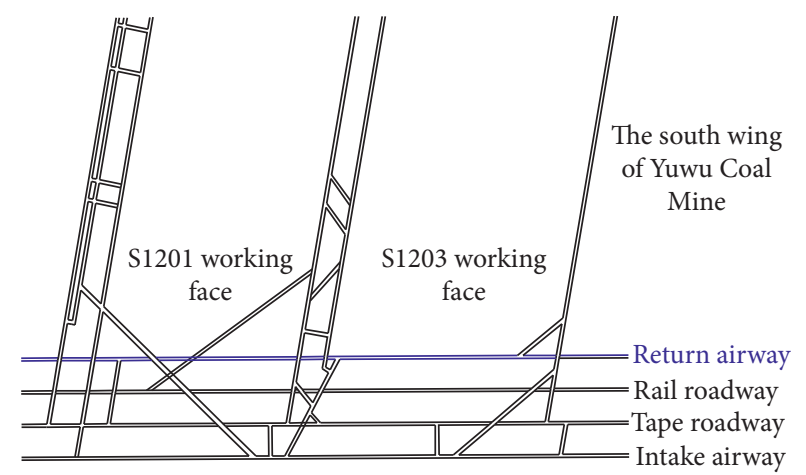

FIgURE 1: General situation of south wing return airway of Yuwu coal mine.

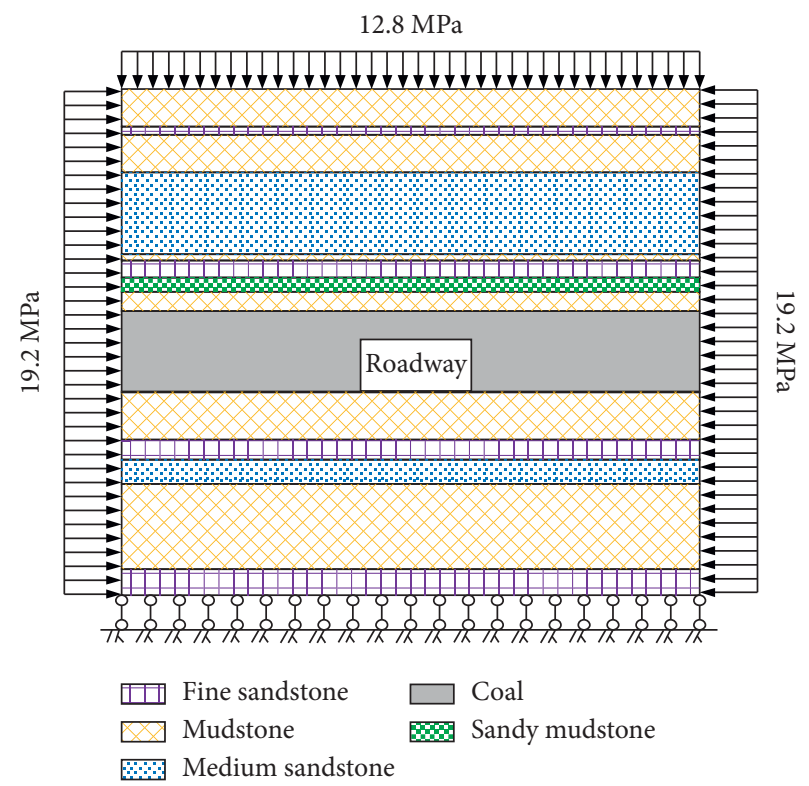

FIGURE 2: Geological section of the south wing general return airway.

\section{Numerical Simulation Scheme Design}

3.1. Numerical Model Establishment of Excavation of the Roadway. According to Saint Venant's principle, the width and height of the numerical model are more than 5 times the size of the roadway, and numerical software FLAC $^{3 \mathrm{D}}$ is used to establish numerical model (shown in Figure 4) for the total return airway in the south wing of Yuwu in order to reduce the influence of setting boundary condition on deformation and failure of surrounding rock in roadway. The width, height, and length of the model are $45.2 \mathrm{~m}, 38.5 \mathrm{~m}$, and $45.0 \mathrm{~m}$, respectively, including 153000 elements and 161874 modes. For the mechanical boundary condition, the bottom surface in the model is fixed, and 19.2 MPa horizontal force is applied to around model, while $12.8 \mathrm{MPa}$ vertical force is applied on the top surface. For the permeable boundary condition, the top surface is set as the permeable boundary, and the remaining surfaces are set as the impervious boundary. In the simulation of excavation roadway, each tunneling 


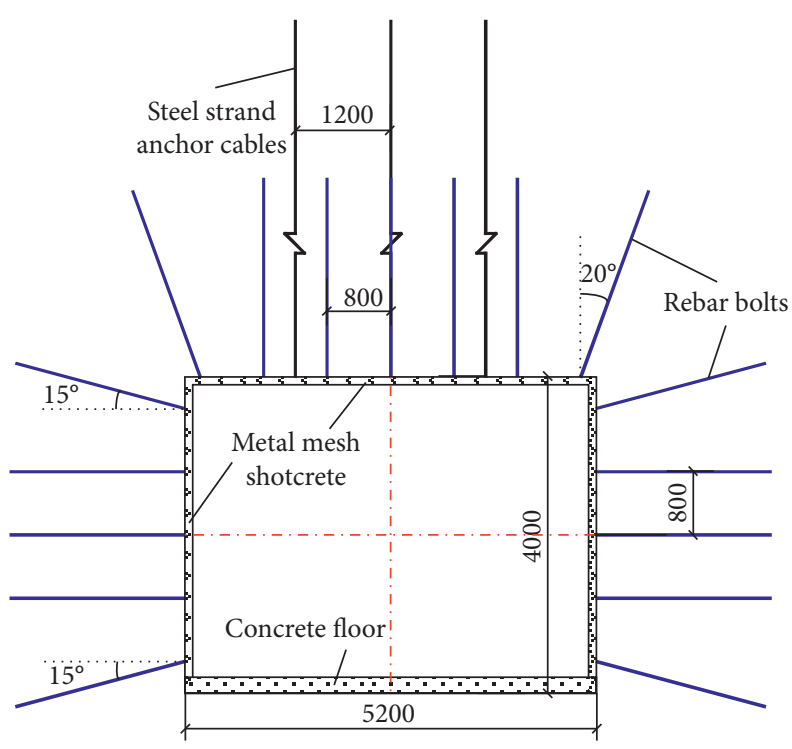

FIGURE 3: The support of anchor-net-cable-spraying for the south wing general return air tunnel.

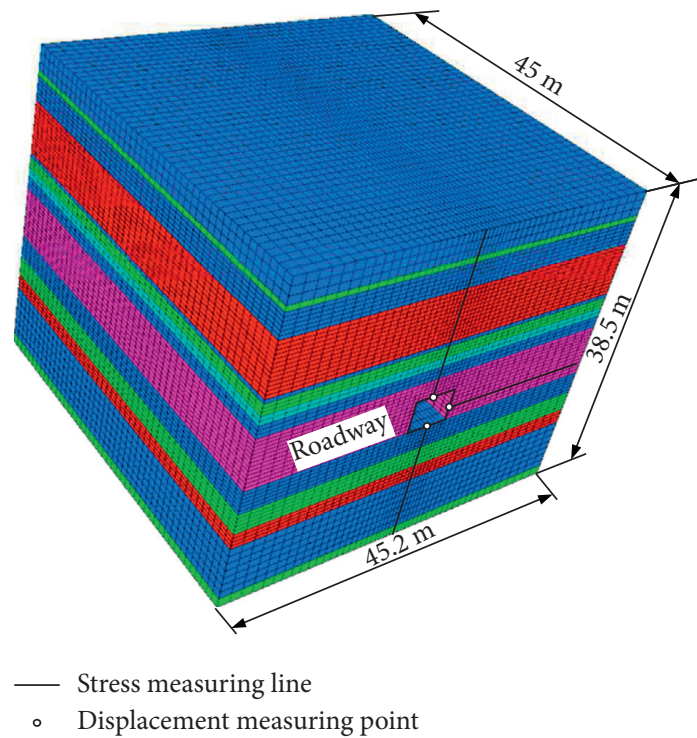

(a)

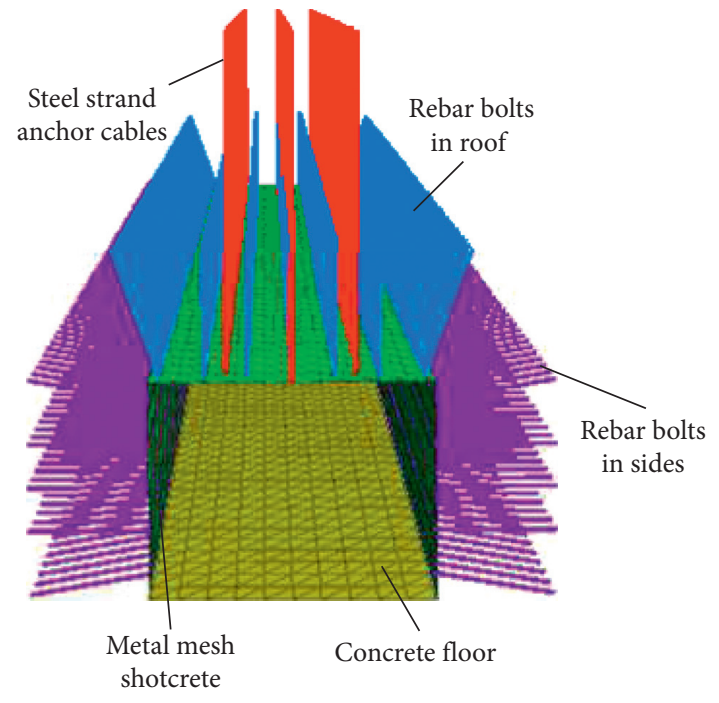

(b)

Figure 4: Numerical model of roadway excavation. (a) Grid model. (b) Supporting structure.

distance is $3 \mathrm{~m}$, while anchor bolt and cable are simulated by cable element (with elastic modulus of $210 \mathrm{GPa}$, anchor agent cohesion of $5.0 \mathrm{MPa}$, internal friction angle of $33^{\circ}$, contact surface stiffness of $1000 \mathrm{GPa}$, and tensile strength of $360 \mathrm{MPa}$ ). Shell elements are used to simulate metal mesh shotcrete (with elastic modulus of $28 \mathrm{GPa}$ and Poison's ratio of 0.25 ) and concrete floor (with elastic modulus of $30 \mathrm{GPa}$ and Poison's ratio of 0.2 ). Besides, a measuring point and a measuring line are arranged on the top, bottom, and two sides of the initial driving face of roadway, respectively (shown in Figure 4(a)), in order to further study and analyze the stress and displacement variation characteristics of surrounding rock.
3.2. Determination of Mechanical Parameters of Surrounding Rock in the Roadway. In recent years, the trilinear strain softening model (shown in Figure 5) has been widely applied in numerical simulation of mine engineering, due to its simple parameter setting and its ability to reflect the strength variation characteristics of rock $[19,20]$. Before reaching the ultimate bearing capacity, the rock is in the elastic stage $O A$, in which the stress $\sigma$ and volume strain $\varepsilon_{v}$ increase and decrease linearly with the increase of strain $\varepsilon$, respectively. At this stage, the cohesion $c$ and the internal friction angle $\varphi$ remain unchanged with initial value $c_{0}$ and $\varphi_{0}$, respectively. Over the ultimate bearing capacity, rocks start to produce plastic strain and enter into softening stage $A B$, in which the 


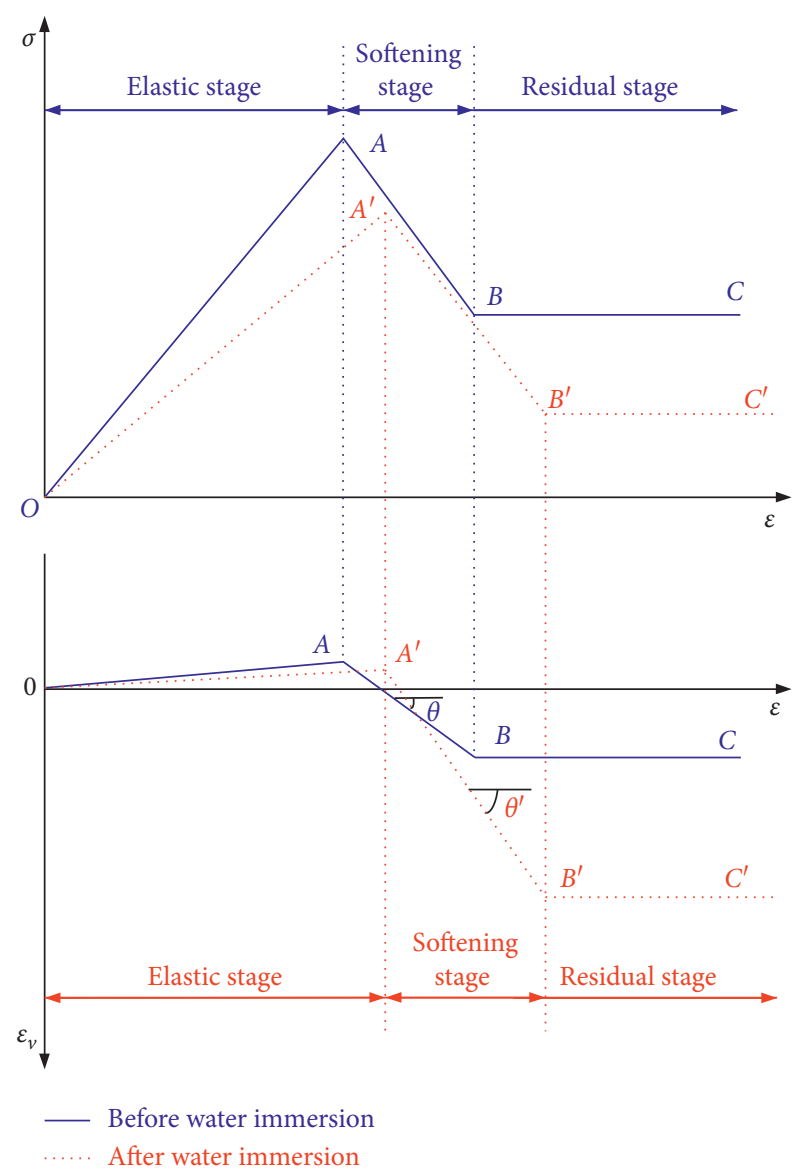

FIGURE 5: Changes of strength and volumetric strain with strain of weakly cemented soft rock before and after water absorption.

stress $\sigma$ decreases rapidly with the increase of strain, while volume strain $\varepsilon_{v}$ increases rapidly in the form of relationship shown in equation (1). At this point, the cohesion $c$ and the internal friction angle $\varphi$ gradually reduce to residual value of $c_{r}$ and $\varphi_{r}$, respectively. The rocks will enter the residual stage $B C$ upon the plastic strain increasing to $s$ certain value. In the stage $B C$, both the stress $\sigma$ and the volume strain $\varepsilon_{v}$ will stop increasing with an increase in strain, while the cohesion $c$ and the internal friction angle $\varphi$ gradually keep the value of $c_{r}$ and $\varphi_{r}$, respectively.

$$
\varepsilon_{v}=\left(\frac{2 \sin \theta}{1-\sin \theta}\right) \varepsilon_{p},
$$

where $\varepsilon_{v}, \theta$, and $\varepsilon_{p}$ are volume strain, dilatancy angle, and plastic strain, respectively.

For the rocks with good water stability, such as medium sandstone, fine sandstone, and coal rock, the variation characteristics of strength and volume strain before and after water absorption are not obvious, while, for weakly cemented mudstone and sandy mudstone (shown in Figure 5), water has limited influence on strength and volume strain (the strength only decreases by $15 \% \sim 20 \%$ after water immersion [13]), due to its complete structure and low permeability in the elastic stage. However, because of the cementing and expansion of clay minerals around the through-crack, the attenuation range of strength and volume strain will increase significantly in the strain softening stage, which is indirectly reflected by the decrease of residual cohesion $c_{r}$ and internal friction angle $\varphi_{r}$ and the increase of dilatancy angle $\theta$ [17-19]. According to the indoor test results of rock $[10,12,20-24]$, the mechanical parameters, used in simulation, of different surrounding rocks in the total return airway in the south wing are shown in Table 1.

3.3. Numerical Simulation Scheme Design. In order to study the influence of the softening and swelling of weakly cemented soft rock on the stability of roadway surrounding rock, based on the background of engineering, 4 different schemes are designed as follows:

(1) Scheme 1: the mechanical parameters of sandy mudstone and mudstone before water absorption are used, regardless of water softening and expansion;

(2) Scheme 2: only considering water softening, the mechanical parameters of sandy mudstone and mudstone after water absorption are used, regardless of variation of dilatancy angle.

(3) Scheme 3: only considering expansion, the mechanical parameters of sandy mudstone and mudstone before water absorption are used, and the variation of dilatancy angle is considered.

(4) Scheme 4: considering water softening and expansion, the mechanical parameters of sandy mudstone and mudstone after water absorption are used.

\section{Numerical Results Analysis}

4.1. Influence of Softening and Expansion on Stress of Surrounding Rock in the Roadway. After finishing the excavation, maximum shear stress distribution curves of surrounding rock of weakly cemented soft rock in roadway under different numerical simulation schemes are shown in Figure 6. Since the stress of surrounding rock is redistributed after excavation, the shear stress is highly centralized in the roadway surface. The rock shear failure will occur when shear stress exceeds the shear strength of rocks, leading to reduce in carrying capacity. The high shear stress will distribute in depth of the surrounding rock and gradually attenuates, and the maximum is located in a certain distance away from the roadway surface. At the position where the maximum shear stress is concentrated, the surrounding rock in the surface is at the state of plastic failure, and the more serious the failure degree, the smaller the shear stress. However, the surrounding rock from the maximum shear stress concentration position to the depth is in an elastic state, and the farther away from the roadway surface, the smaller shear stress, which finally reduces to initial stress state.

It can be seen from Figure 6 that, without considering the softening and expansion of weakly cemented soft rock (Scheme 1), the maximum shear stress concentration values of roof, floor, and two sides are 9.1 MPa, 11.2 MPa, and 6.7 $\mathrm{MPa}$, respectively, which are located at the distance of 
TABLE 1: Mechanical parameters of surrounding rock of roadway.

\begin{tabular}{|c|c|c|c|c|c|c|c|c|c|}
\hline Rock types & $\begin{array}{l}\text { Density } \\
\left(\mathrm{kg} / \mathrm{m}^{3}\right)\end{array}$ & $\begin{array}{l}\text { Elasticity } \\
\text { modulus/ } \\
\text { GPa }\end{array}$ & $\begin{array}{l}\text { Poisson's } \\
\text { ratio }\end{array}$ & $\begin{array}{c}\text { Prepeak } \\
\text { cohesion/ } \\
\mathrm{MPa}\end{array}$ & $\begin{array}{l}\text { Prepeak } \\
\text { internal } \\
\text { friction } \\
\text { angle }{ }^{\circ}\end{array}$ & $\begin{array}{l}\text { Residual } \\
\text { cohesion/ } \\
\mathrm{MPa}\end{array}$ & $\begin{array}{c}\text { Residual } \\
\text { internal } \\
\text { friction angle/ }\end{array}$ & $\begin{array}{c}\text { Tensile } \\
\text { strength/ } \\
\mathrm{MPa}\end{array}$ & $\begin{array}{c}\text { Dilatancy } \\
\text { angle }^{\circ}\end{array}$ \\
\hline $\begin{array}{l}\text { Sandy } \\
\text { mudstone }\end{array}$ & 2280 & $4.1(3.3)$ & 0.28 & $1.64(1.39)$ & $31(30)$ & $1.0(0.4)$ & $28(25)$ & $1.2(1.0)$ & $6(45)$ \\
\hline Mudstone & 2150 & $3.7(3.0)$ & 0.30 & $2.05(1.74)$ & $30(29)$ & $1.2(0.5)$ & $26(24)$ & $1.6(1.4)$ & $5(55)$ \\
\hline $\begin{array}{l}\text { Fine } \\
\text { sandstone }\end{array}$ & 2600 & 6.5 & 0.23 & 1.96 & 35 & 0.6 & 32 & 1.6 & 12 \\
\hline $\begin{array}{l}\text { Medium } \\
\text { sandstone }\end{array}$ & 2510 & 5.9 & 0.25 & 1.78 & 34 & 0.5 & 31 & 1.5 & 10 \\
\hline Siltstone & 2480 & 5.0 & 0.24 & 1.82 & 34 & 0.6 & 31 & 1.4 & 11 \\
\hline Coal mine & 1450 & 2.4 & 0.28 & 1.42 & 31 & 0.6 & 30 & 1.0 & 7 \\
\hline
\end{tabular}

Note. The number in the bracket is the corresponding parameter value of soft rock after water absorption.

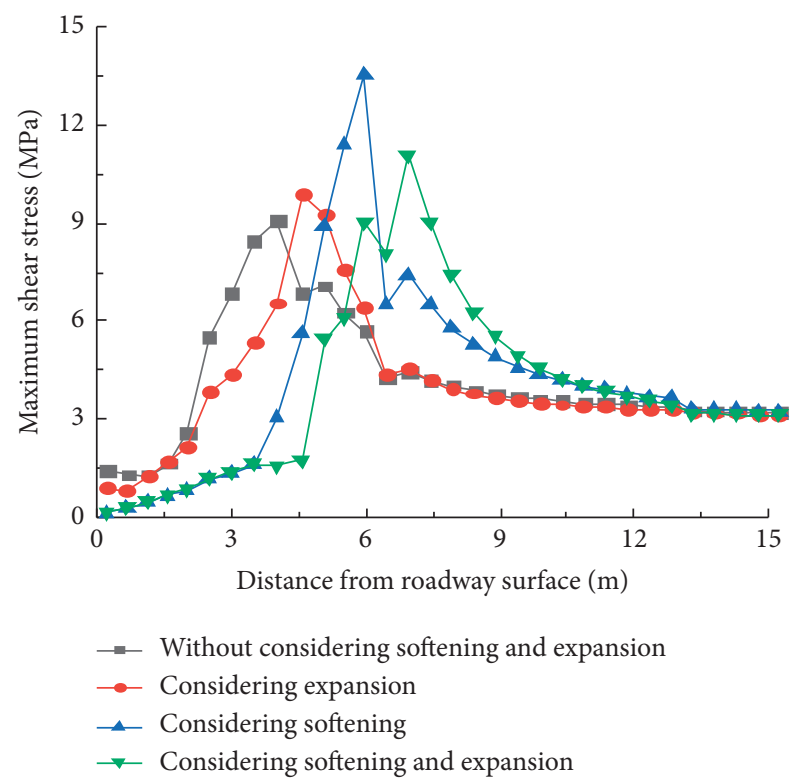

(a)

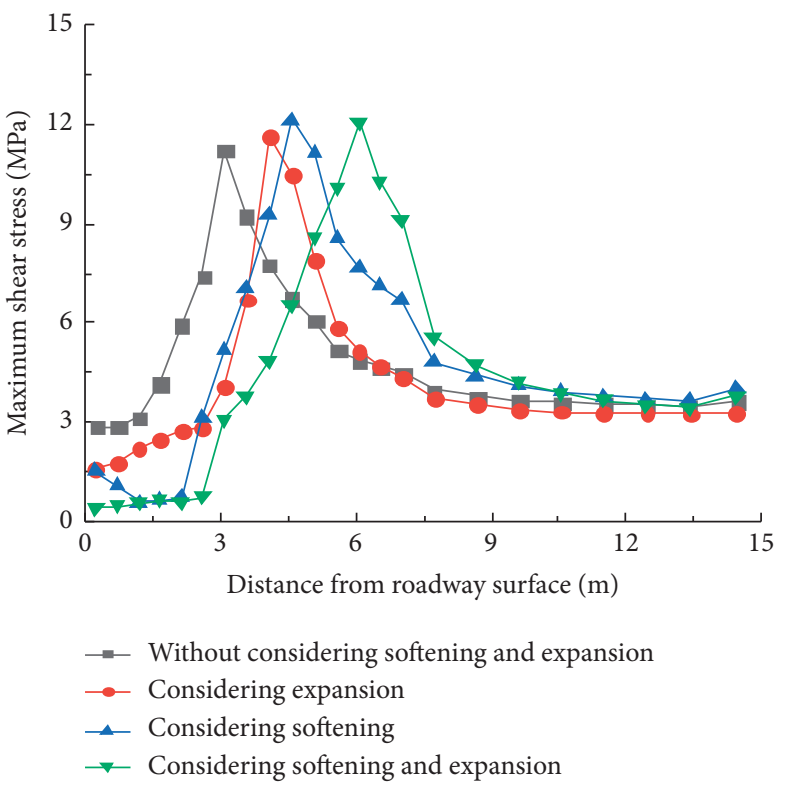

(b)

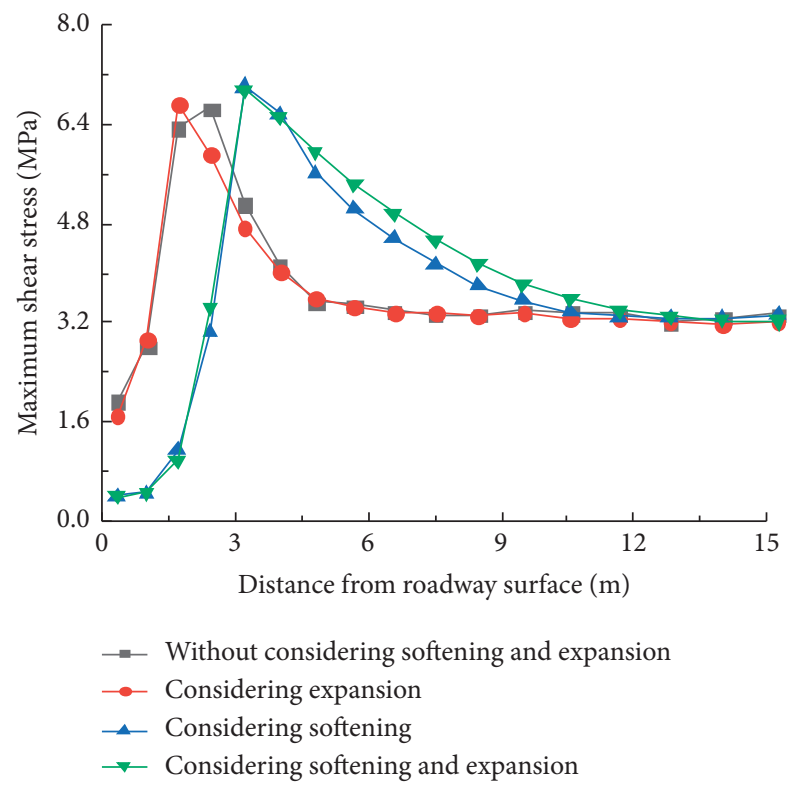

(c)

FIgURE 6: Maximum shear stress distribution curves of weakly cemented soft rock in the roadway under different simulation schemes. (a) Roof. (b) Floor. (c) Two sides. 
$4.0 \mathrm{~m}, 3.1 \mathrm{~m}$, and $2.4 \mathrm{~m}$ from roadway surface. And the surrounding rock, which are in the range of plastic failure, remains the maximum shear stress of $1.3 \mathrm{MPa} \sim 2.8 \mathrm{MPa}$. Compared with Scheme 1, under the condition of Scheme 2 (that is, considering water softening), the maximum shear stress concentration values of surrounding rock have smaller changes, but their locations on roof and floor are $0.5 \mathrm{~m}$ and $1.0 \mathrm{~m}$ far away from the roadway, while they remain unchanged in the two sides of roadway. When only considering expansion (Scheme 3) or both water softening and expansion (Scheme 4), the maximum shear stress of surrounding rock at the range of plastic failure directly reduces to $0.3 \mathrm{MPa}$. And the concentration positions of the maximum shear stress in roof, floor, and two sides are about $2.0 \mathrm{~m} \sim 3.0 \mathrm{~m}, 1.5 \mathrm{~m} \sim 3.0 \mathrm{~m}$, and $0.8 \mathrm{~m}$ away from the roadway, respectively. This indicates that the softening and expansion, especially softening, of weakly cemented soft rock will reduce the carrying capacity of shallow surrounding rock and increase the degree of failure, resulting in the significant increase of surrounding rock loose zone and the decline of carrying capacity or local failure in supporting structure.

\subsection{Influence of Softening and Expansion on Deformation of Surrounding Rock in the Roadway}

4.2.1. Vertical Displacement. Figure 7 shows the vertical displacement distributions of surrounding rock of weakly cemented soft rock in roadway after finishing the excavation under different numerical simulation schemes. Under the condition of Scheme 1, the vertical displacement of surrounding rock mainly occurs in the shallow area of $2 \mathrm{~m}$ at the roof and floor. The maximum vertical displacement is at the center of roof and floor of roadway, which are $66.9 \mathrm{~m}$ and $30.9 \mathrm{~mm}$, respectively, while the vertical displacement in the depth or two sides of roadway decreases rapidly to 0 . It is indicated that the conventional bolt-net cable shotcrete support technology can effectively ensure the safety of weakly cemented soft rock in roadway without considering water (no softening and expansion). Under the conditions of Schemes 2 to 4 , the locations of the maximum vertical displacement of surrounding rock are still at the center of roof and floor, which are $162.0 \mathrm{~mm}$ and $254.3 \mathrm{~mm}$, respectively, improved by $142.2 \%$ and $723.0 \%$ compared with those in Scheme 1. The maximum vertical displacements at the center of roof and floor are $253.1 \mathrm{~mm}$ and $96.9 \mathrm{~mm}$ under Scheme 3, improved by $278.3 \%$ and $213.6 \%$, respectively. For Scheme 4, the maximum vertical displacements of surrounding rock are $517.4 \mathrm{~mm}$ and $496.2 \mathrm{~mm}$ in the center of roof and floor, respectively, which are increased by $673.4 \%$ and $1505.8 \%$. Moreover, considering the expansion of soft rock, the attenuation rate of vertical displacement of surrounding rock will significantly slow down with the increase of depth, leading to a great displacement at $2 \mathrm{~m}$ away from the roadway surface and a larger loosening range of surrounding rock. Therefore, it can be seen that the softening of soft rock is the main reason for roof subsidence, while the floor heave is mainly related to expansion. Considering both softening and expansion, these two will cause obvious synergistic effect, resulting to displacement damage, such as sharp increase in vertical displacement of roof and floor, roof caving, and floor heave.

4.2.2. Horizontal Displacement. The horizontal displacement distributions of surrounding rock of weakly cemented soft rock in roadway after finishing the excavation under different numerical simulation schemes are shown in Figure 8 . Under the condition of Scheme 1, the horizontal displacement of surrounding rock is mainly produced in the top with depth of $1.5 \mathrm{~m}$ and two sides of roadway. The maximum horizontal displacement is at the center of the surface of the two sides, of which the value is $40.4 \mathrm{~mm}$, indicating that the surrounding rock of the two sides in roadway can keep stability under the conventional bolt-net cable shotcrete support. Compared with Scheme 1, under the condition of Scheme 2, the maximum horizontal displacement of surrounding rock only increases by $1.7 \mathrm{~mm}$ at two sides, while that increases significantly in the top with 1.5 depth and floor, especially near the corner of roadway, where the value increases directly to $32.0 \mathrm{~mm}$.

In the case of Scheme 3, the horizontal displacement distribution law of surrounding rock is the same as that in Scheme 1, but the maximum horizontal displacement at the center of two sides in roadway is $153.0 \mathrm{~mm}$, which is 3.8 times that in Scheme 1. However, the horizontal displacement of surrounding rock in roadway increases significantly in top and floor with depth of $3.0 \mathrm{~m}$ and two sides, of which the maximums are $206.6 \mathrm{~mm}$ and $141.4 \mathrm{~mm}$, under the condition of Scheme 4 . The above results show that the expansion of weakly cemented soft rock around the roadway has a limited influence on horizontal displacement of two sides, while the softening will weaken greatly the bearing arch action of the surrounding rock, leading to serious horizontal displacement of two sides. When both the softening and expansion occur, the horizontal displacement of two sides will further increase due to the coupling effect, resulting in accidents, such as bulging and wall caving.

\subsubsection{Maximum Displacement of the Roadway Surface over} Time. Figure 9 shows the displacement variation curve of measured points in surrounding rock during excavation of roadway. It is can be seen that, regardless of softening and expansion, the displacements of surrounding rock at roof, floor, and two sides of roadway are always small (the maximum is less than $70 \mathrm{~mm}$ ), which keep the constants after excavating forward $9 \mathrm{~m}$. This indicates that the supporting structure and surrounding rock have formed an effective bearing system, which can restrain effectively the deformation extension of surrounding rock in roadway. Under the condition of considering expansion, the maximum displacement of surrounding rock at two sides keeps unchanged, but that at roof and floor increases to $250 \mathrm{~mm}$, which remains roughly stable after excavating forward $21 \mathrm{~m}$, while, considering softening, the maximum displacements at roof, floor, and two sides are 2-3 times higher than that of 


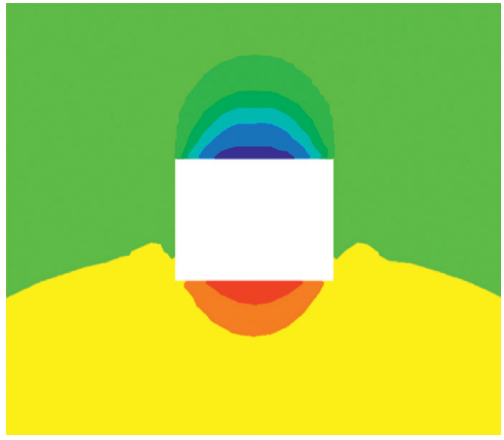

(a)

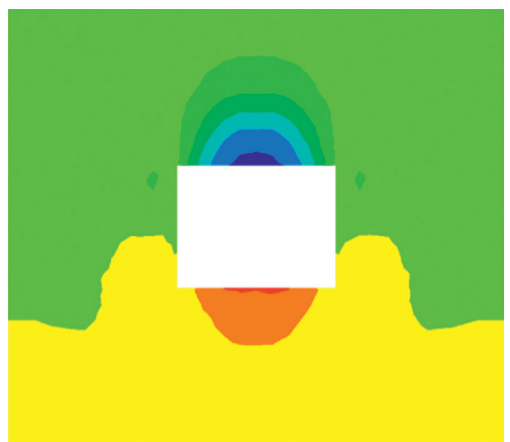

(c)
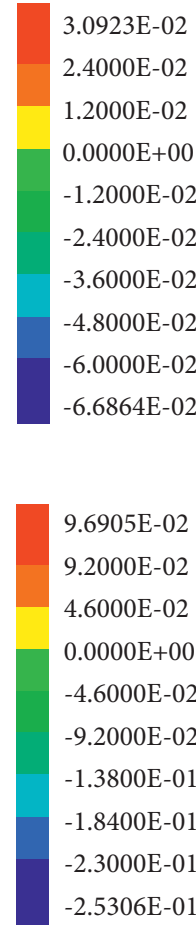

$-2.5306 \mathrm{E}-01$

FIGURE 7: Vertical displacement distributions of surrounding rock of weakly cemented soft rock in the roadway under different simulation schemes. (a) Without softening and expansion. (b) With expansion. (c) With softening. (d) With softening and expansion.

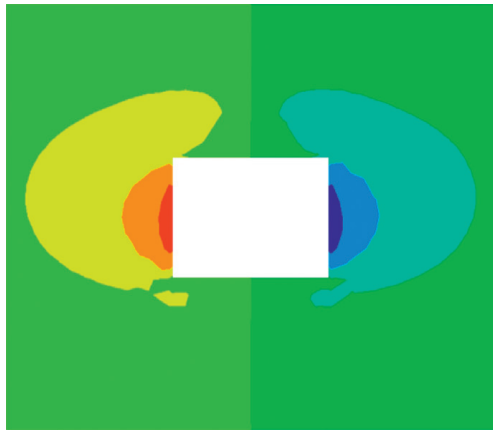

(a)

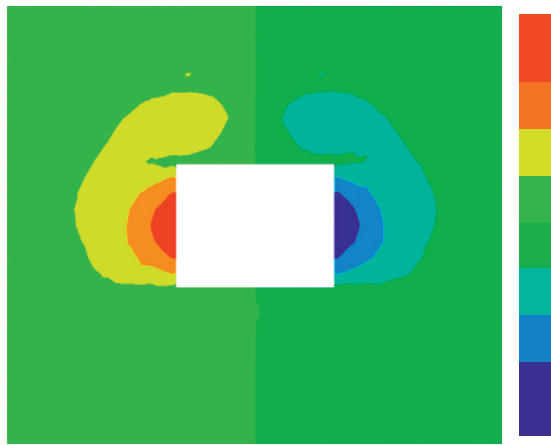

(c)

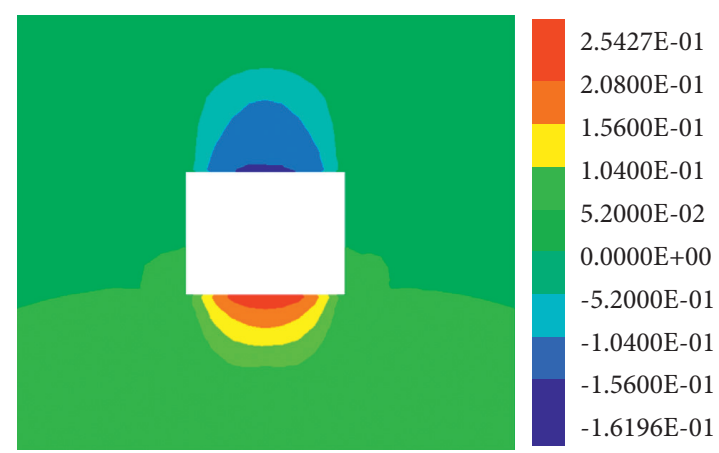

(b)

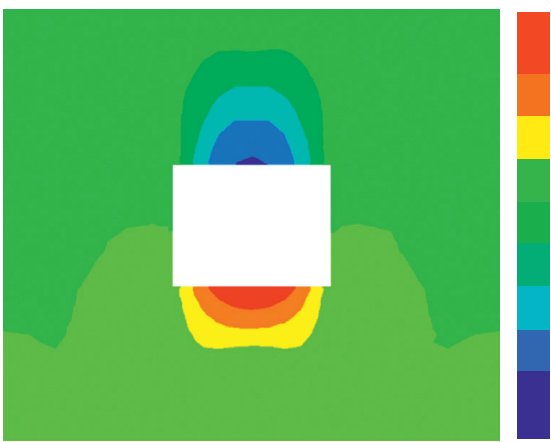

$4.9621 \mathrm{E}-02$

$3.7500 \mathrm{E}-01$

$2.5000 \mathrm{E}-01$

$1.2500 \mathrm{E}-01$

$0.0000 \mathrm{E}+00$

$-1.2500 \mathrm{E}-01$

$-2.5000 \mathrm{E}-01$

$-3.7500 \mathrm{E}-01$

$-5.0000 \mathrm{E}-01$

$-5.1740 \mathrm{E}-01$

(d)

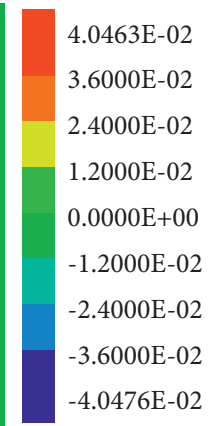

$-4.0476 \mathrm{E}-02$

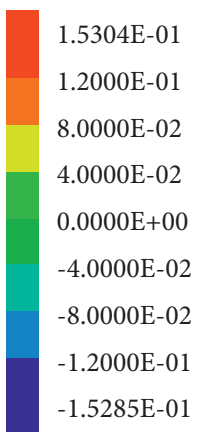

$-1.5285 \mathrm{E}-01$
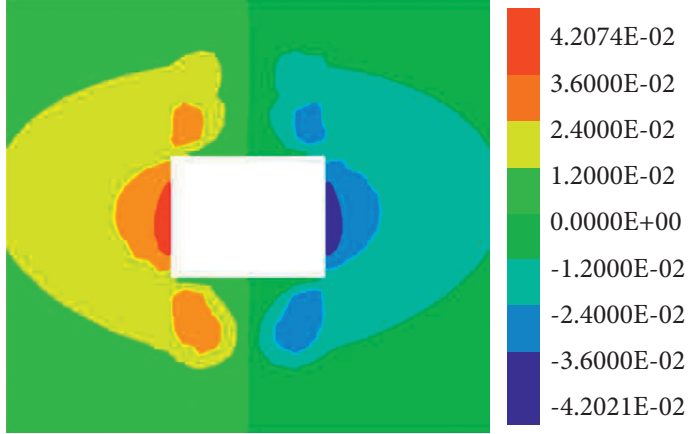

(b)

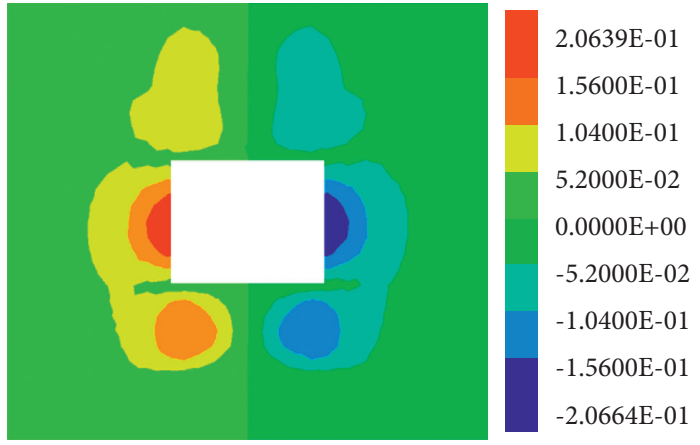

(d)

FiguRE 8: Horizontal displacement distributions of surrounding rock of weakly cemented soft rock in the roadway under different simulation schemes. (a) Without softening and expansion. (b) With expansion. (c) With softening. (d) With softening and expansion. 


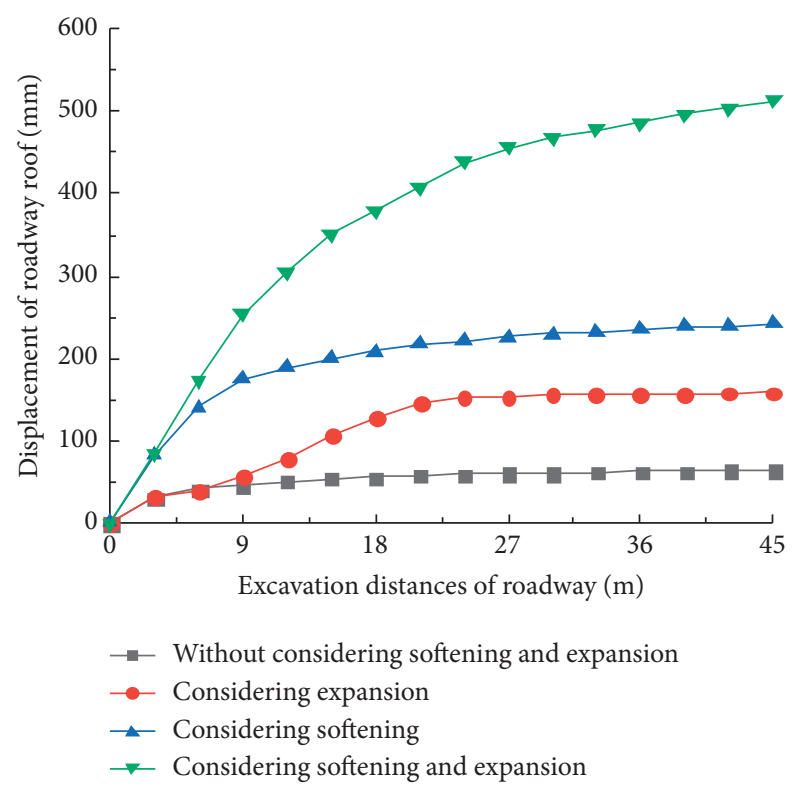

(a)

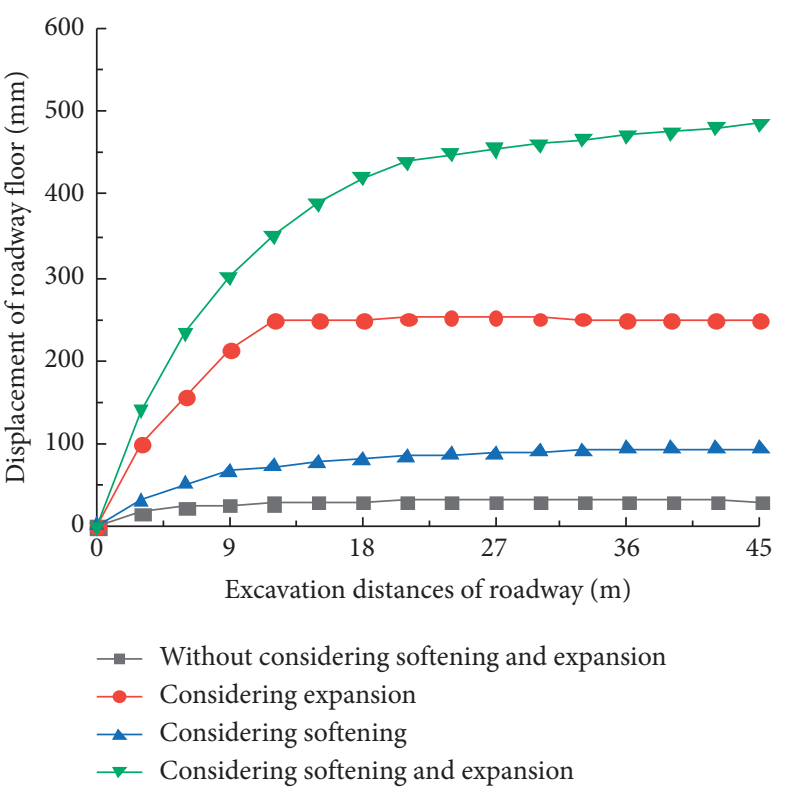

(b)

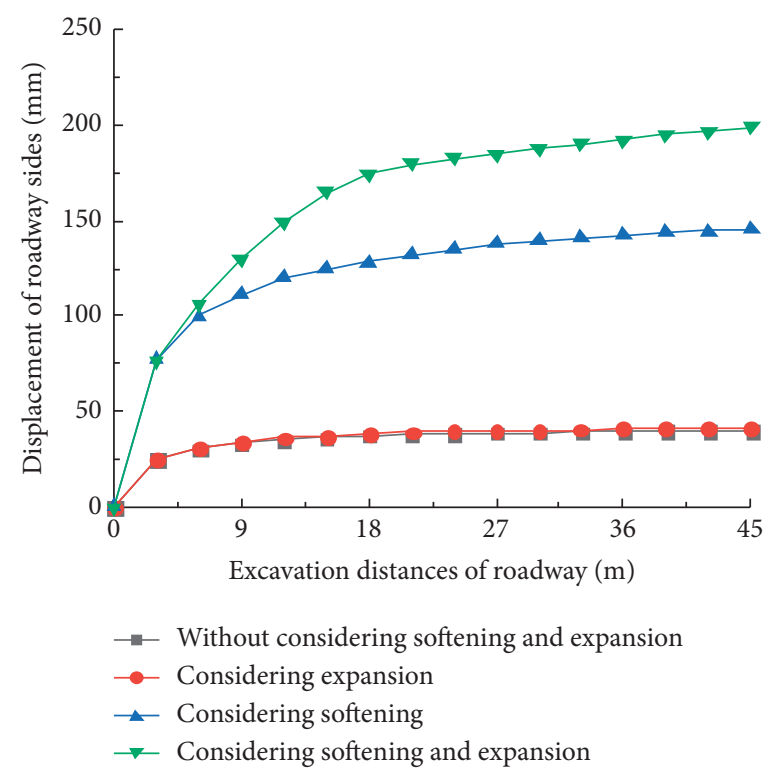

(c)

FIGURE 9: Change curves of surface displacement of weakly cemented soft rock in the roadway under different schemes. (a) Roadway roof. (b) Roadway floor. (c) Roadway sides.

Scheme 1, which still increase gradually with the increase of excavation distances after excavating forward $21 \mathrm{~m}$. Compared with Scheme 1, the maximum displacements at roof, floor, and two sides increase by 7 times, 15 times, and 4 times under the condition of considering both softening and expansion, which continue to increase with excavating, leading to large deformation instability of roadway. Therefore, it is necessary to consider the effect of softening and expansion of weakly cemented soft rock on the stability of surrounding rock and supporting structure when tunneling in water-rich and weakly cemented soft rock stratum, in order to avoid serious economic losses caused by roadway repair or instability.
4.3. Influence of Softening and Expansion on Failure of the Surrounding Rock in the Roadway. The distributions of plastic zone for surrounding rock of weakly cemented soft rock in roadway after finishing the excavation under different numerical simulation schemes are shown in Figure 10. Regardless of softening and expansion, the failure depths of plastic zones of surrounding rock in roof, floor, and two sides are $2.7 \mathrm{~m}, 2.8 \mathrm{~m}$, and $2.0 \mathrm{~m}$, respectively, and these plastic zones are not cut-through, indicating that the surrounding rock is at the effective supporting range by existed support of anchor cable. Under the condition of considering expansion, the failure depth of plastic zone in two sides of surrounding rock is 


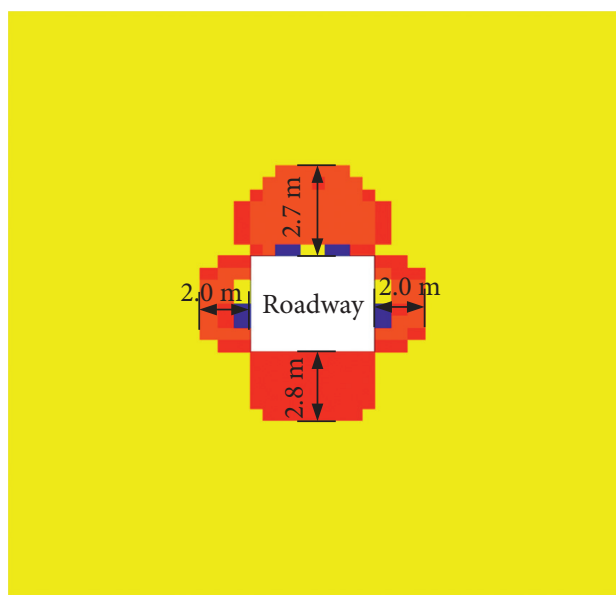

(a)

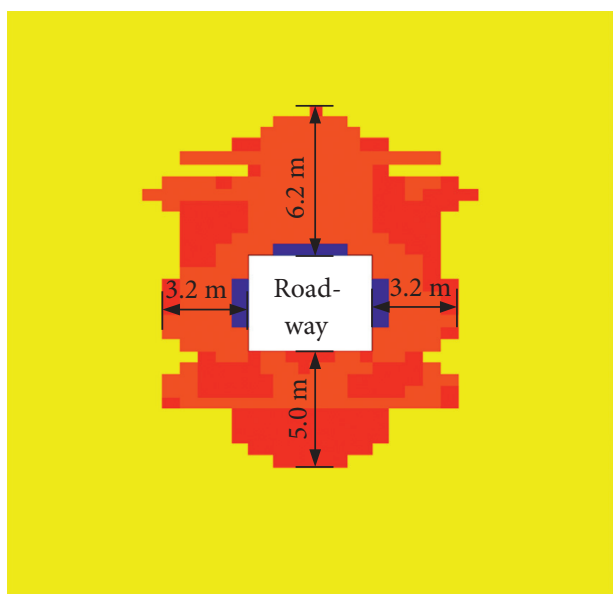

(c)

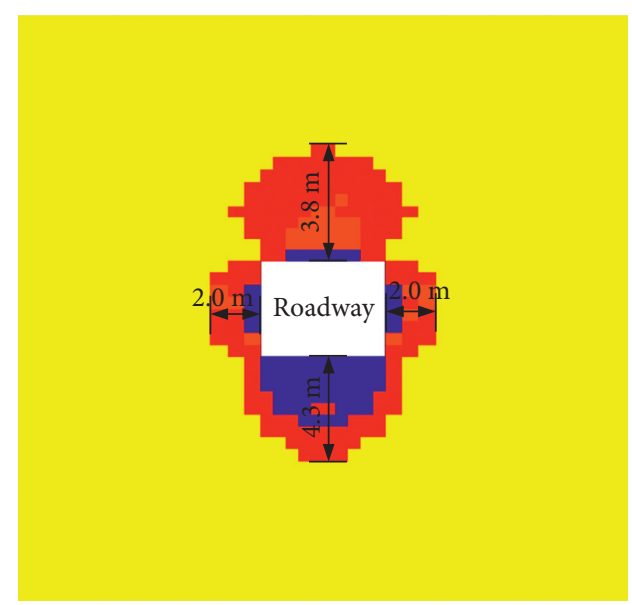

(b)

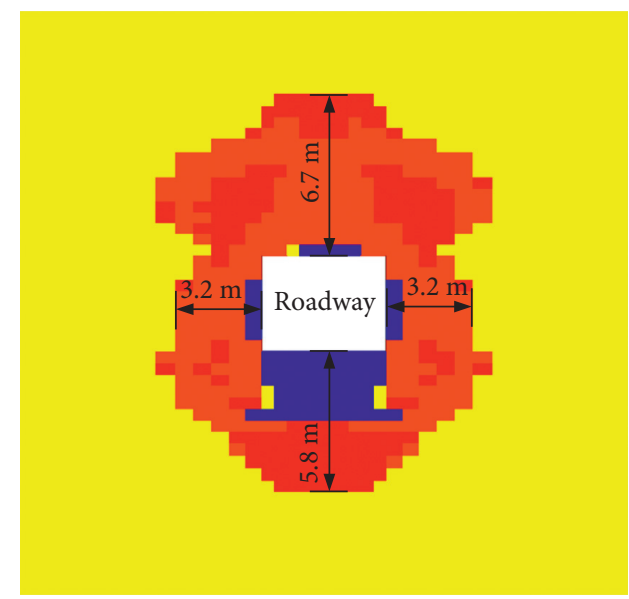

(d)

FIGURE 10: Distribution of plastic zone of weakly cemented soft rock roadway surrounding rock under different simulation schemes (red: shear failure, blue: shear-tension failure). (a) Scheme 1: without softening and expansion. (b) Scheme 2: with expansion. (c) Scheme 3: with softening. (d) Scheme 4: with softening and expansion.

still $2.0 \mathrm{~m}$, but that in roof and floor extends to $3.85 \mathrm{~m}$ and $4.36 \mathrm{~m}$, respectively. This indicates that the expansion of weakly cemented soft rock stratum affects the bearing capacity of support structure in two sides, but it will seriously affect the interaction and bearing capacity of the supporting and itself. When the softening is considered, the failure depths of plastic zones in roof, floor, and two sides are $6.2 \mathrm{~m}, 5.0 \mathrm{~m}$, and $3.2 \mathrm{~m}$, respectively. And these plastic zones are cut-through, indicating that it is difficult for the surrounding rock of roadway to form an effective bearing arch system, leading to a large increase in the stress of the existing supporting structure and a greater probability of failure. With considering softening and expanding of weakly cemented soft rock, the plastic failure range in roof and floor further increases to $6.7 \mathrm{~m}$ and $5.8 \mathrm{~m}$, resulting in weakening in the bearing capacity of surrounding rock and exacerbating roadway deformation.

\section{Studying on Supporting Countermeasures of Weakly Cemented Soft Rock in the Roadway}

5.1. Design of the New Supporting Scheme. It can be seen from the above that the original supporting scheme of the total return airway in the south wing of Yuwu can effectively suppress its deformation and failure expansion to ensure the safety of roadway. However, under the condition of water, the shallow strata with weakly cemented soft rock of roadway will produce water fracture channel due to shear stress concentration, of which large amounts of clay minerals cement and expand, leading to great increase in scope and degree of damage of surrounding rock in roadway. The large deformation sustains increase to ultimate failure destruction of supporting structure and instability of roadway. It can be concluded that the key to stability control of the surrounding rock with water-rich and weakly cemented soft rock in roadway is to reduce the failure range and degree of 


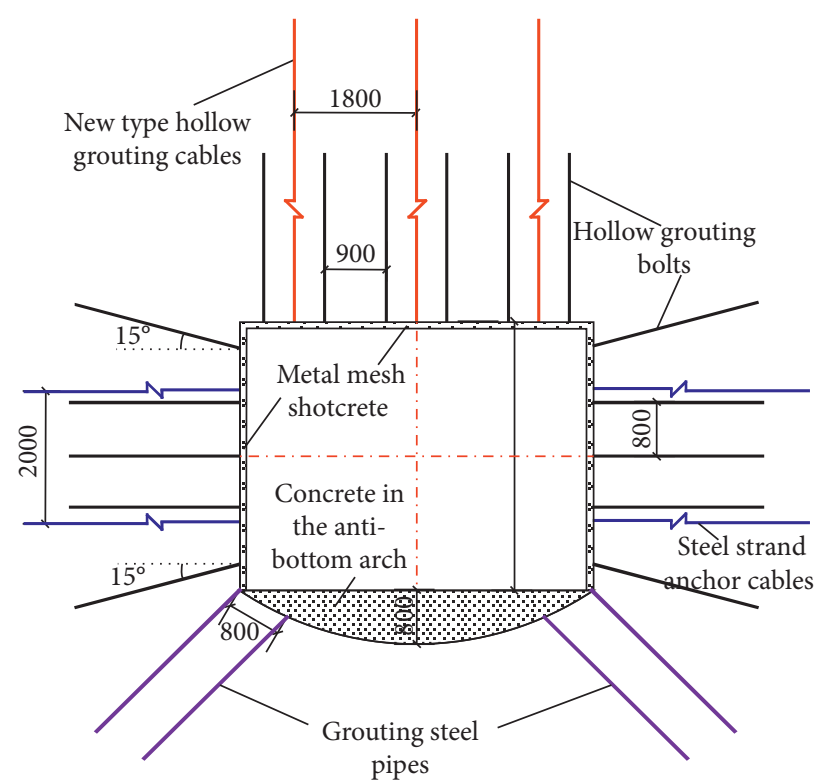

FIGURE 11: "Grouting + anchor cable mesh + bottom arch" combined support scheme for weakly cemented and soft rock in the roadway.

weakly cemented soft rock, and to prevent the fissure water in the fine sandstone around the roadway from penetrating into the roadway through the water-conducting fissure of the weakly cemented soft rock. Therefore, a new combined support scheme of "Grouting + anchor cable mesh + bottom arch" is put forward for total return airway in the south wing of Yuwu, as shown in Figure 11:

(1) Grouting and water plugging of surrounding rock. Since the bolt body of the hollow anchor bolt adopts a hollow design, the hole in the bolt body is used as a high-pressure wind and water channel and a grouting channel. Compared with a solid bolt body, the hollow bolt body design can obtain better rigidity and shear strength. Therefore, the screw steel bolts in the roof and two sides of roadway in original support scheme are changed into hollow grouting bolts with $\Phi 20 \mathrm{~mm} \times 2500 \mathrm{~mm}$, of which the row spacing is $800 \mathrm{~mm}$, but that in roof and two sides is $900 \mathrm{~mm}$ and $800 \mathrm{~mm}$, respectively. The anchor cables in roof of roadway are changed into new hollow grouting anchor cable with $\Phi 22 \mathrm{~mm} \times 8000 \mathrm{~mm}$ and row spacing $1800 \mathrm{~mm} \times 1600 \mathrm{~mm}$. Two grouting steel pipes, with $\Phi 32 \mathrm{~mm} \times 3000 \mathrm{~mm}$ and row spacing $800 \mathrm{~mm} \times 800 \mathrm{~mm}$, are arranged at the bottom of both sides of the roadway, respectively. The grouting materials is Malisan cement slurry, and the grouting pressure is $1.0 \sim 3.0 \mathrm{MPa}$.

(2) Strengthen support of anchor cable in two sides. Two prestressed steel strand anchor cables, with $\Phi 17.8 \mathrm{~mm} \times 2000 \mathrm{~mm}$, row spacing ,2000 mm $\times 1600 \mathrm{~mm}$, and preload not less than $110 \mathrm{kN}$, are added between the two sides of hollow grouting anchor bolts.

(3) Closed roadway surface with metal mesh shotcrete. A layer of $50 \mathrm{~mm}$ thick concrete is initially sprayed on the roof and two sides of the roadway. In addition, a metal mesh with size of $100 \mathrm{~mm} \times 100 \mathrm{~mm}$ is laid. After the completion of the construction of anchor and cable, another layer of $50 \mathrm{~mm}$ thick concrete is sprayed.

(4) Overbreak and backfilled of the bottom arch. The bottom of the roadway is overdug to from an antibottom arch with the height of $800 \mathrm{~mm}$, and C25 plain concrete is backfilled in the antibottom arch.

5.2. Effect Analysis of Engineering Application. Based on the numerical simulation of Scheme 4, the excavation process of roadway under the combined support scheme of "grouting + anchor cable mesh + bottom arch" is simulated again (during the simulation, the cohesion of the rock in the grouting reinforcement range was increased by 1.2 times, the internal friction angle was increased by $0.5^{\circ}$, and the permeability coefficient was reduced by 20 times), and the displacement and plastic zone distribution after the excavation of surrounding rock in roadway with weakly cemented soft rock are shown in Figure 12. It can be seen that the maximum displacement of surrounding rock under the new support scheme still appears at the center of the roof, floor, and two sides of roadway, but the values reduce to $41.4 \mathrm{~mm}, 31.9 \mathrm{~mm}$, and $47.3 \mathrm{~mm}$, respectively, which are $92.0 \%, 93.6 \%$, and $77.1 \%$ lower than those under the condition of Scheme 4. Under the new support scheme, the depth of plastic zone of surrounding rock in roof, floor, and two sides is $2.7 \mathrm{~m}, 1.6 \mathrm{~m}$, and $2.6 \mathrm{~m}$, respectively, which are reduced by $59.7 \%, 72.4 \%$, and $18.7 \%$ compared with Scheme 4. It can be concluded that the combined support scheme of "grouting + anchor cable mesh + bottom arch" can significantly reduce the softening and expansion of weakly cemented soft rock and ensure the safe tunneling and normal use of weakly cemented soft rock in roadway. 

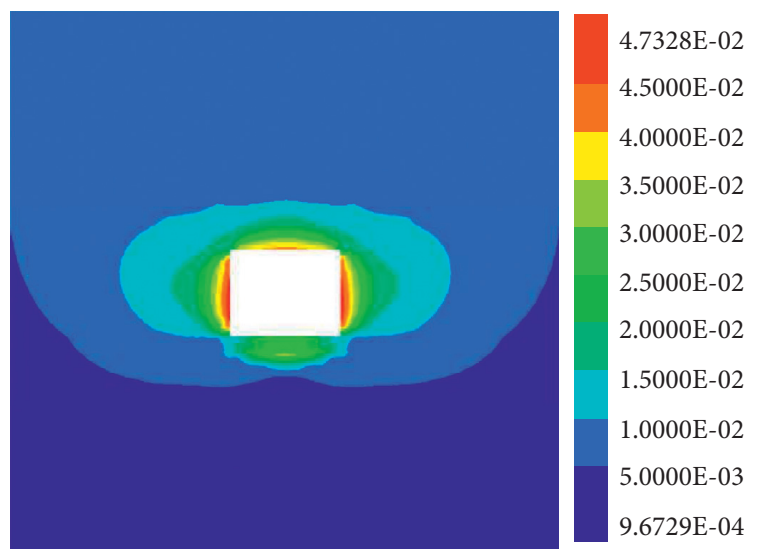

(a)

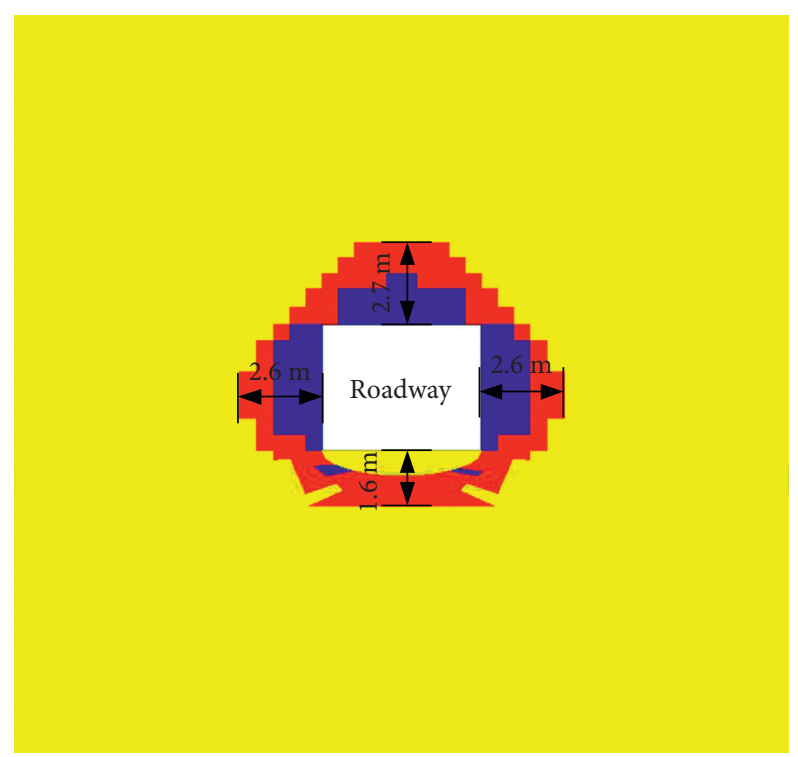

(b)

FIGURE 12: Numerical calculation results of displacement and plastic zone of surrounding rock in roadway with weak cemented soft rock roadway under new support scheme. (a) Displacement. (b) Plastic zone.

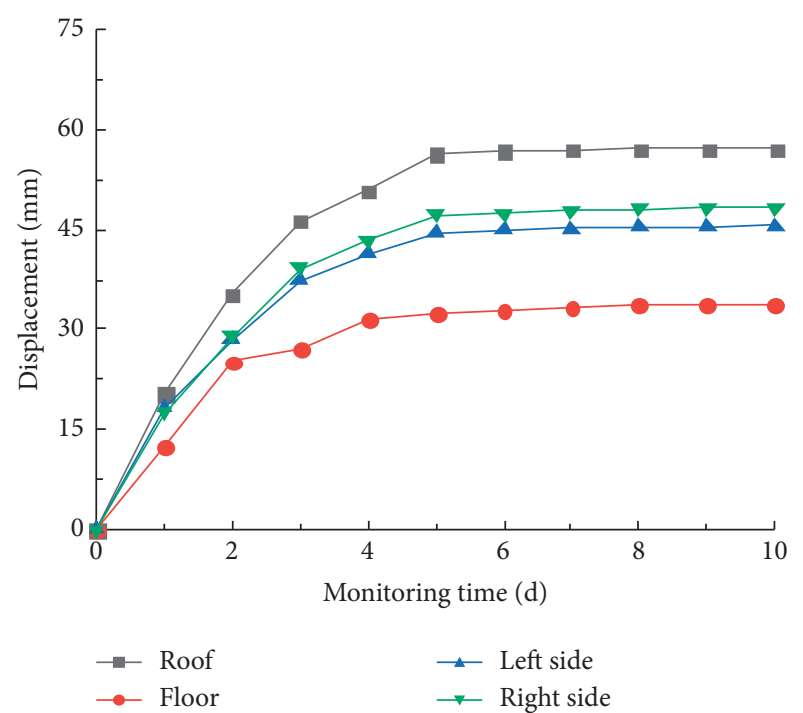

FIGURE 13: Monitoring curves of surrounding rock displacement of roadway under the new support scheme.

(4) In order to further study the stability of surrounding rock in roadway under the combined support scheme of "grouting + anchor cable mesh + bottom arch," the displacement of excavation section in the actual roadway is monitored. The displacement of the actual roadway over time is shown in Figure 13. It can be seen that the displacements of roof, floor, and two sides in roadway remain at stable values of $57.2 \mathrm{~mm}, 33.9 \mathrm{~mm}$, and $48.4 \mathrm{~mm}$, respectively, after excavation of 5 days under the combined support of "grouting + anchor cable mesh + bottom arch." This measured data is similar to the numerical simulation results in this paper, further indicating that the combined support of "grouting + anchor cable mesh+bottom arch" can effectively control the stability of surrounding rock with weakly cemented soft rock in roadway, which is more scientific and reasonable.

\section{Conclusions}

(1) Under the condition of considering softening and expansion, the maximum shear stress of surrounding rock in the plastic failure range of roadway directly reduces to $0.3 \mathrm{MPa}$, and its concentration position at roof, floor, and two sides is about $3.0 \mathrm{~m}$ and $0.8 \mathrm{~m}$ outward, respectively, compared with those in the nonwater environment.

(2) The maximum displacements of surrounding rock with weakly cemented soft rock in roof, floor, and two sides of roadway are $66.9 \mathrm{~m}, 30.9 \mathrm{~mm}$, and $40.4 \mathrm{~mm}$, respectively, in anhydrous environment. However, in the water-rich environment, due to the obvious synergistic effect of softening and expansion of weakly cemented soft rock, these values increase to $517.4 \mathrm{~mm}$, $496.2 \mathrm{~mm}$, and $206.6 \mathrm{~mm}$, respectively, which continue to increase with tunneling of roadway.

(3) Considering the influence of softening and expansion of weakly cemented soft rock, the depths of plastic failure zones of the roof, floor, and two sides are $6.8 \mathrm{~m}$, $5.8 \mathrm{~m}$, and $3.2 \mathrm{~m}$, respectively, which are $2.5,2.1$, and 1.6 times those under anhydrous environment.

(4) Compared with the conventional bolt mesh cable shotcrete support, the maximum displacements of roof, floor, and two sides with weakly cemented soft rock decrease by $92.0 \%, 93.6 \%$, and $77.1 \%$ under the combined support scheme of "grouting + anchor cable mesh + bottom arch," respectively, and the depths of the plastic zone are reduced by $59.7 \%, 72.4 \%$, and $18.7 \%$. 


\section{Data Availability}

The data used to support the findings of this study are included within the article.

\section{Conflicts of Interest}

The authors declare that they have no conflicts of interest.

\section{Acknowledgments}

Li Yan acknowledges the Key Research and Development Program of Xuzhou (No. KC18090). Zhang Lianying was supported by the National Natural Sciences Foundation of China (Nos. 51974296 and 52074240) and the Innovation Capacity Building Program of Xuzhou (No. KC18241). Ma Chao was supported by the Key Research and Development Program of Xuzhou (No. KC20176). The research was supported by the Open Research Fund of the State Key Laboratory of Coal Resources and Safe Mining, CUMT (No. SKLCRSM20KF007).

\section{References}

[1] X. Zhang, L. I. Jun, J. Liu, and W. Peng, "Research on deformation characteristics of strong expansive soft rock roadway and its control strategy," Journal of China University of Mining \& Technology, vol. 46, no. 3, pp. 494-500, 2017.

[2] G. Zhang, G. Guo, and Y. Lv, "Study on the strata movement rule of the ultrathick and weak cementation overburden in deep mining by similar material simulation: a case study in China," Mathematical Problems in Engineering, vol. 2020, Article ID 7356740, 21 pages, 2020.

[3] L. I. Qing, J. Hou, T. Han, W. Xu, Z. Zhou, and M. Dong, "Research on deformation mechanism and support technology of coal roadway with weakly cemented rock strata in Yangjiacun mine," Coal Engineering, vol. 48, no. 07, pp. 4043, 2016.

[4] B. Luo, Y. Sun, Z. Xu et al., "Damage characteristics and mechanism of the 2017 groundwater inrush accident that occurred at dongyu coalmine in Taiyuan, Shanxi, China," Water, vol. 13, no. 3, p. 368, 2021.

[5] B. Liang, Q. Cao, J. Wang, and L. Jiang, "Experimental study on slaking characteristics of feeble disintegration soft rock in drying-wetting cycle," China Safety Science Journal, vol. 27, no. 8, pp. 91-96, 2017.

[6] Q. Meng, J. Wang, L. Han, W. Sun, W. Qiao, and G. Wang, "Physical and mechanical properties and constitutive model of very weakly cemented rock," Rock and Soil Mechanics, vol. 41, no. S1, pp. 19-29, 2020.

[7] B. Wang, "Calculation analysis on water swelling deformation of road in soft rock," China Coal, vol. 37, no. 05, pp. 58-60+93, 2011.

[8] Y. Xue, J. Liu, P. G. Ranjith, Z. Zhang, F. Gao, and S. Wang, "Experimental investigation on the nonlinear characteristics of energy evolution and failure characteristics of coal under different gas pressures," Bulletin of Engineering Geology and the Environment, vol. 81, no. 1, p. 38, 2022.

[9] Y. Xue, J. Liu, X. Liang, S. Wang, and Z. Ma, "Ecological risk assessment of soil and water loss by thermal enhanced methane recovery: numerical study using two-phase flow simulation," Journal of Cleaner Production, vol. 334, Article ID 130183, 2022.
[10] W. Zhao, W. Liang, M. Xu, and B. Liu, "Stability analysis of roadway in weakly consolidated formation based on clay mineral content," Safety In Coal Mines, vol. 51, no. 12, pp. 277-282, 2020.

[11] Y. Li, S. Wang, J. Zou, H. Wang, H. Li, and N. Wu, "Correlation research between shear strength and moisture content of swelling mudstone," Science Technology and Engineering, vol. 21, no. 7, pp. 2857-2864, 2021.

[12] J. Zhang, S. Cheng, H. Wang, Z. Gao, F. Zhou, and H. Zhou, "Experiment of microstructure and hydrologic characteristics of weakly cemented soft rocks in western China," Coal Geology \& Exploration, vol. 48, no. 03, pp. 116-121, 2020.

[13] J. Liu, H. Jing, B. Meng, L. Wang, X. Zhang, and J. Yang, "Research on the effect of moisture content on the creep behavior of weakly cemented soft rock and its fractional-order model," Rock and Soil Mechanics, vol. 41, no. 08, pp. 2609-2618, 2020.

[14] L. Jing and S. Chen, "Composite support technology and monitoring analysis of water-rich soft rock roadway," Safety In Coal Mines, vol. 49, no. 08, pp. 231-233+238, 2018.

[15] X. Zhu, Z. Yang, Z. Pan, J. Zhao, and Z. Yang, "Full anchored cable support technology for dynamic pressure roadway with weakly cemented water-rich roof," Coal Technology, vol. 39, no. 03, pp. 26-30, 2020.

[16] X. Zhu, Z. Yang, H. Zhong, and J. Zhao, "Deformation characteristics and control technology of surrounding rock in retaining roadway with weak cemented water rich roof," China Energy and Environmental Protection, vol. 41, no. 11, pp. 167-170+174, 2019.

[17] G. Zhu, S. Li, J. Bai, X. Wang, and Y. Bai, "Study on rational support technology of mine weakly consolidated watery roadway," Coal Science and Technology, vol. 44, no. 03, pp. 7-11, 2016.

[18] Y. Hu, "Study on roof-fall mechanism and supporting countermeasure of rich water soft rock roadway," Coal Mining Technology, vol. 23, no. 03, pp. 63-66, 2018.

[19] C. Sun, S. Zhang, B. Jia, and Z. Wu, "Physical and numerical model tests on post-peak mechanical properties of granite," Chinese Journal of Geotechnical Engineering, vol. 37, no. 05, pp. 847-852, 2015.

[20] W. Jing, W. Xue, and Z. Yao, "Variation of the internal friction angle and cohesion of the plastic softening zone rock in roadway surrounding rock," Journal of China Coal Society, vol. 43, no. 08 , pp. 2203-2210, 2018.

[21] X. Ma, S. Zhang, and X. Ma, "Experimental study on water principle characteristics of Neogene weak cementation rock," Yellow River, vol. 38, no. 05, pp. 125-127+142, 2016.

[22] L. Wang and Z. Li, "Triaxial compression test analysis of weakly cemented mudstone in West China," Journal of Yangtze River Scientific Research Institute, vol. 33, no. 08, pp. 86-90+95, 2016.

[23] G. Liu and L. I. Ming, "Experimental study of coal rock uniaxial and triaxial compression," Safety In Coal Mines, vol. 44, no. 07, pp. 4-6, 2013.

[24] J. Liu, Y. Xue, Q. Zhang, H. Wang, and S. Wang, "Coupled thermo-hydro-mechanical modelling for geothermal doublet system with 3D fractal fracture," Applied Thermal Engineering, vol. 200, Article ID 117716, 2022. 